\title{
Visits to Centres of Excellence in Mental Handicap
}

Ann Christine Evans, Consultant Psychiatrist with a Special Interest in Mental Handicap, Halifax General Hospital, Halifax, West Yorkshire

In December 1986 I was invited by Yorkshire Regional Health Authority to visit centres of excellence with regard to mental handicap community provision. I had just been appointed to a consultant psychiatrist post with a special interest in mental handicap. The Authority's suggestion was that I go to several centres around Britain and make one trip to Europe and one trip to North America. I was very favourably impressed by Yorkshire's imaginative style and set to work to plan my tour. I had until 1 April 1987 when my new job started. I learned very quickly that preparing a travel schedule is a frustrating and irritating task. It took more than four weeks of telephone calls, with the aid of detective work by Directory Enquiries, before I had even a rough plan of campaign. I discovered several truths at this time. These were:

(1) Anybody with any influence in Health or Social Services takes a month off over Christmas and New Year. They are also very susceptible to 'flu in the winter.

(2) The more power a person has the more likely he or she is to be helpful in planning visits. He or she is presumably less busy than the rest of us and has more time to spare.

(3) There is a definite north-south divide. Most of the people who had taken similar trips abroad lived in the South of England. This area was blanketted by snow for most of January and was often inaccessible by telephone. I cursed the weather.

(4) Spouses and children do not necessarily share one's delight at being asked to spend time travelling and looking at services.

(5) I did not have much in the way of organising ability. I do now.

I was beginning to doubt the wisdom of the Yorkshire Regional Health Authority when, at the end of January, everything suddenly fell into place. Financing of the trips, which I had expected to be a major hurdle, proved to be no problem. I visited nine districts in England. I will not dwell on these as most are well known as being innovative and progressive. However, I must mention two schemes which greatly impressed me:

(a) the Bolton Network Scheme is a unique example of collaboration between Social Services and the District Health Authority. It was set up to provide in the community for residents discharged from institutions.

(b) the De Vitrie Cottages Scheme in Lancaster. Here the five most behaviourally disturbed residents of the Royal Albert Hospital, Lancaster have been housed successfully in two cottages in the community for the past year.
I set off for 12 days in Toronto at the beginning of March. Canada is clean and conservative. Most things seem to cost less than they do here. There is little in the way of eccentricity however. My tour was arranged by Dr Joseph Baker, a psychologist who is Co-ordinator of Services for the Disabled in Ontario, and I visited areas up to 100 miles from Toronto.

I cannot really comment on psychiatry in Canada. In the time I was there I met only one psychiatrist and that was for just 10 minutes. She spent one afternoon per week in a mental handicap institution which housed 800 residents. That was the total of the institution's psychiatric provision. Psychiatry does not form a significant part of the mental handicap scene, either in the institution or in the community. There appear to be two distinct classes of psychiatrist (or any sort of doctor for that matter) in Canada. There are those who work for the government hospitals who constitute the lower echelon and there are those in private practice. There are also hybrids of varying degrees. Similar rules apply to psychologists. Psychiatrists have little training in the psychiatry of mental handicap and so it is an unpopular specialty. It is also not very lucrative. I was regarded by everybody I met as being an altruistic freak for being a psychiatrist interested in mental handicap. They all said they could have done with my help.

In Britain community ordinary homes are mainly set up by the Health Authorities and Social Services. In Canada they are largely set up by voluntary agencies, usually groups of parents who have become disillusioned by the care their offspring have received in institutions. These agencies are run as non-profit-making limited companies. They are paid by the government to provide residential and day care for ex-residents of institutions. I received the distinct impression that the sideways step of contracting out to agencies made the setting up of group homes an easier task. Careworkers, both in institutions and in the community, have usually done a one year training in mental handicap at polytechnic level. They were invariably surprised when I mentioned that nurses often looked after the mentally handicapped in Britain. They were equally surprised that the places in which they lived were called hospitals. In Canada they are just known as institutions.

Overall they are not so far ahead of what we are doing here. They have been moving people out into the community for longer than we have, and they spend a little more on their group homes. But the picture is not as impressive as I had expected. They appear to have made the same mistakes as we have, e.g. in making many group homes too large. But 
most people seem now to accept that three to four people living together is about the right size. Like us they have left the most behaviourally disturbed people in the institutions to bring out last. The consensus of opinion now seems to be that most people with challenging behaviour can be looked after in the community, provided conditions are good enough. This involves adequate staffing and small, heterogenous groups, i.e. not putting disturbed people together. But it becomes difficult to attain heterogenous groups when all you have left in the institutions are people with challenging behaviours.

There are still a lot of mentally handicapped people living in institutions in Canada. The conditions in those institutions can be far worse than anything you will find in Britain. I have never seen physical restraints used with the frequency with which they are used in the largest Ontario institution. I can only presume that this happens because of the lack of psychiatric and psychological input. The worst thing was that I, as a visitor, was expected to admire what I saw. Those people who are in the community seem to be doing well. One hardly ever hears of people having to go back into the institutions. Occasionally behaviour disturbance causes problems and it is here that the inputs from psychiatry and psychology are missed. But they manage pretty well without them. Perhaps the moral is that money reduces behaviour disturbance in mentally handicapped people better than drugs or behaviour modification programmes-money, that is, in the form of pleasant, interesting, stimulating surroundings and high staffing levels.

Government programmes in Canada are overseen by a watchdog in the form of another voluntary agency, originally formed by parents, which has now grown to considerable proportions. This is the National Institute of Mental Retardation in Toronto. It has recently changed its name to the G. Allan Roeher Institute. It is a large organisation, housed on the campus of the University, which funds a great deal of research. It is very much a centre of academy. These are people who are firmly committed to the idea that all mentally handicapped people can live very ordinary lives in the community. They have many lawsuits in progress at present concerning the integration of handicapped children into ordinary schools alongside non-handicapped children. There is much television coverage of their activities which frequently involve considerable criticism of provincial policy. The director is currently engaged in a research project considering what comes after normalisation. Some of the papers they publish show a shift in emphasis from the concept of group homes towards the concept of fostering of mentally handicapped people. They also stress the way in which they feel the attitude of society has to change, so that mentally handicapped people are not seen as being in a sick role any more. This change of attitude is of course much easier for them because, even under the old system, the handicapped lived in institutions and not hospitals, and were looked after by careworkers and not nurses, and were seen only infrequently by doctors. Thus the medical emphasis was always much less.
Another idea which impressed me concerned the whole ethos of closing down institutions. In Canada, such closure programmes are achieved as quickly as possible in order to minimise the amount of suffering caused to residents and staff. I was told that five large institutions in Ontario (each having approximately 1,000 residents) had been closed between 1983 and 1985, each in a period of six monthsthat is, six months from the first announcement of imminent closure, to the discharge of the final patients. Few problems were encountered and this was felt to be the kindest way of dealing with residents' and staff's morale and fears. It also costs less money.

My second overseas visit was to Stockholm which is a very European city where all sorts of eccentricities are tolerated. It is enormously expensive, a cup of coffee costing twice as much as here, and three times as much as in Canada. My visit was planned for me by Doctor Karl Grunewald, the recently retired Director of Mental Retardation Services in Sweden. He was originally a child psychiatrist but has been at the head of planning for services for the past two decades. He has strongly influenced worldwide trends regarding mental handicap. His ethos has always been that the care of mentally handicapped people should be the province of professionals with a social sciences background rather than medical. It has been fairly easy for him to initiate change in this respect because he is a doctor. It is easy to change things from the inside.

I looked at Stockholm and various counties up to 200 miles north of Stockholm. The most striking thing about mental handicap provision in Sweden is the extravagance of their schemes. They spend a great deal of money on group homes, both in material and staffing. I was not convinced that this level of finance was essential to the good working of their system. I thought that the attitudes of people working in mental handicap were more important, but it was impossible to separate the two in Sweden. As an example of their attitudes, there is talk at the moment of imminent legislation stating that all mentally handicapped people have a right to their own personal small kitchen and bathroom in addition to sleeping-cum-living-room areas, the minimum size of these being laid down by law.

As in Canada, I felt that community provision in Sweden was not as far ahead of us as I had anticipated. There were again large numbers in institutions and again it was those with the worst behaviour problems who had been left behind. I saw no use of physical restraints in Sweden however. Institutions are usually organised into villas instead of wards. These form small, separate, single-storey blocks, each perhaps housing 12 people. There are consultant psychiatrists who have direct responsibility for mentally handicapped people and who play a considerable role in the planning of services, but as in this country their input is being reduced. The care-workers who work directly with residents are non-medical, having done a two year course at polytechnic level, similar to Canada. As in Canada they were amazed to hear that nurses often did this work in Britain, and that mentally handicapped people often lived in hospitals. As in this country, most of the community 
provision is carried out directly by Health and Social Services. Group homes in Sweden are much more often of the correct size, that is they contain three to four people. Far more often than I have seen anywhere else, people are accommodated in single units, e.g. flats, perhaps situated near a group home, where some degree of supervision can be carried out by care-workers.

Another facet of Swedish provision which was good was their standard of day-care facilities. These are organised in small groups of perhaps 20 to 22 people attending each Day Centre. Within the Day Centres they are divided into smaller groups of four or five people who work in small rooms. This was one of the things that their experience had taught them. People work together better in small groups and in small spaces. Their Day Centres are invariably bright, cheerful, modern buildings, and constitute very caring environments. They provide a great contrast to our Social Education Centres and there appeared to be no shortage of places at them. Absenteeism and Sickness rates, on the part of both care-workers and clients, were very low as they enjoyed being there very much.

I have tried to draw together the various points which impressed me on my visits. I would like to thank Yorkshire Regional Health Authority for their generosity in making it possible for me to look at services in other countries.

\section{Conference Report}

\section{ISSTIP International Conference on Medicine and the Performing Arts*}

P. Grahame Woolf, Consultant Psychiatrist, 2a Vanbrugh Hill, Blackheath, London SE3, and regular contributor to Music \& Musicians International

The International Society for the Study of Tension in Performance (ISSTIP) was founded to address serious problems which beset professional musicians, actors and dancers and its first European conference was held at $\mathrm{St}$ Bartholomew's Hospital last summer. In the USA the interest aroused has led to Music Medicine developing as rapidly as Sports Medicine.

For a psychiatrist, this three-day conference was a fascinating coming together of remedial practitioners and musicians from all over the world and it exemplified both the advantages and some difficulties of multiprofessional collaboration.

Curative enthusiasts of numerous persuasions and some sufferers too shared theoretical and practical discussion and demonstrations in parallel sessions. Medical experts lectured and held clinics about common problems of musicians and dancers. Rigorous research studies were described, bringing a welcome scientific approach to a field in which many individuals extol the virtues of idiosyncratic eponymous treatments. Complementary medicine was represented by practitioners of relaxation, meditation and acupuncture. Renowned artists discussed their own experiences of nervousness and helped participants with

-Held at St Bartholomew's Hospital, London from 24-26 August 1987. problems. Sometimes the juxtaposition of topics was almost surreal, in the settings of the hospital lecture theatre and the august Great Hall of Bart's. During the conference, a regrettable polarisation of interests between doctors and artists gradually emerged, few of the medical consultants displaying interest in the presentations of problems by the performers themselves.

The problems are by no means trivial. Dr Ian James of the Royal Free Hospital found that over $70 \%$ of players in four London orchestras are so nervous as to adversely affect their playing, with even more suffering in the provincial orchestras. More than one in five take alcohol or drugs to control performance and audition anxiety, and many report depression (defined as bouts of unexplained sadness) and experience frustration and anger as a frequent problem. This may be self-directed, against colleagues or the conductor, the latter because individual musicianship is inhibited, especially for rank-and-file string players. Many feel unappreciated by colleagues, a majority feel under-valued by conductors and some feel despised by their audiences. These findings highlight the emotional hazards of orchestral playing and the need for a sympathetic director who provides opportunities for discussion of feelings. Large majorities consider that the lifestyle inhibits possibilities to establish satisfactory personal relationships and believe that music colleges offer inadequate and inappropriate training. 